\title{
miRNA-6087 Delivered by Exosomes Derived from Human Bone Marrow Mesenchymal Stem Cells, Inhibition of miR-6087 in Exosomes can Significantly Inhibit the Proliferation, Invasion and Migration of Tumor Cells.
}

\section{Xiaowei Yang}

The First Affiliated Hospital of Nanchang University

Yibiao Zhou

Shenzhen Children's Hospital

Qi Lai

The First Affiliated Hospital of Nanchang University

Sheng Huang

The First Affiliated Hospital of Nanchang University

Xuqiang Liu

The First Affiliated Hospital of Nanchang University

Bolin $\mathrm{Hu}$

Shenzhen children's hospital

Min Dai

the First Affiliated Hospital of Nanchang University

Bin Zhang ( $\square$ acker11@126.com )

The First Affiliated Hospital of Nanchang University

\section{Research article}

Keywords: hBMSC, exsome, osteosarcoma, miR-6087, U20S

Posted Date: December 1st, 2020

DOI: https://doi.org/10.21203/rs.3.rs-116151/v1

License: (c) (i) This work is licensed under a Creative Commons Attribution 4.0 International License. Read Full License 


\section{Abstract}

Background: Mesenchymal stem cells (hBMSCs) function in most of tumor microenvironment囚including osteosarcoma, and interact with proximal cells. Here, in view of exosomes derived from hBMSCs, we studied the miRNA secreted from hBMSCs in the growth of human U2OS cells.

Methods: hBMSCs were cultured in a-DMEM containing fetal bovine serum. After 48 hours, the cell culture supernatants containing the exosomes were harvested and exosome purification was performed by PEGbased vesicle enrichment. Osteosarcoma (U2OS) cells were treated with exosomes derived from hBMSCs enriched with or without miR-6087. Cell viability was measured by the scratch migration assay, Transwell invasion assay, and CCK-8 test. The expression of HSP70/ALIX and miR-6087 in exosomes was determined by western blotting and RT-PCR, respectively.

Results: hBMSC-derived exosomes were found to play a key role in the U2OS cell growth. Inhibition of miR-6087 in exosomes can significantly inhibit the proliferation and invasion of tumor cells.

Conclusion: This was the first time that we demonstrated that exosomes derived from hBMSCs have the power to suppress the growth of U2OS cells by downregulating miRNA-6087. Our research shows a new possibility for the way in which hBMSCs take part in tumor progression.

\section{Background}

Osteosarcoma (OS) is one of the most common, primary high-grade malignant bone neoplasms in children and young adultsand accounting for $5 \%$ of newly diagnosed pediatric cancers ${ }^{[1]}$,is characterized by a high recurrence rate, drug resistance and susceptibility to early metastasis. The standard of care is a three-drug chemotherapy regimen consisting of cisplatin, doxorubicin, and methotrexate ${ }^{[2]}$.Although osteosarcoma treatment has improved, the five-year survival rate has unfortunately been maintained at approximately $65-70 \%{ }^{[3,4]}$.Because osteosarcoma patients develop resistance to chemotherapy drugs, this is one of the main reasons for treatment failure ${ }^{[5,6]}$. Thus, it is urgent to reveal the potential molecular mechanisms of OS and to find an appropriate therapeutic strategy for OS.

MSC refers to natural stem cells and derived cultured cells present in BM in vivo ${ }^{[7]}$. Because it is found in bone marrow (BM) and can differentiate into osteoblasts, chondrocytes and hematopoietic stromal support cells, it is called bone marrow mesenchymal stem cells ${ }^{[7]}$. The characteristics of hBMSC are as follows: 1. It has super differentiation ability and can differentiate into various lineages of mesoderm. 2. It acts on all immune effectors and has immunosuppressive effects in vivo and in vitro. 3. MSC has a stable nutritional effect because it produces a variety of growth factors and cytokines. 4 . These findings have led to the evaluation of MSC potential for treating diseases and the birth of MSC-based therapy. It has been used to treat osteogenesis imperfecta, chromogenic leukocyte dystrophy, graft-versus-host Disease (GVHD) and acute myocardial infarction ${ }^{[8-10]}$. MSCs have also been implanted to treat bone 
defects ${ }^{[11,12]}$. Based on the clinical development of MSC in recent years, scholars have conducted research on MSC in the field of osteosarcoma.

Tu B et al. believe that hBMSCs in the tumor microenvironment may be a new target for improving the

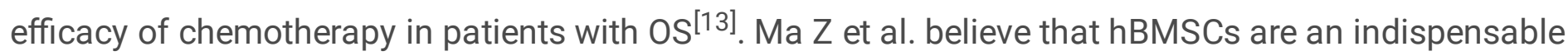
target for cell-to-cell communication during carcinogenesis ${ }^{[14]}$. Pelagalli $A$ et al. found that hBMSCs might induce the migration and invasion of OS cells in the tumor microenvironment ${ }^{[15]}$. Vallabhaneni KC et al. have suggested a tumor-supportive role for hBMSCs in OS growth, which is strongly associated with the miRNA content of the EVs released from the hBMSCs ${ }^{[16]}$. Among them, the exosomes released by hBMSCs deliver miRNAs into target cells, and MVs play an important role in delivery.

Microvesicles (MVs) are secreted from all cell types under various conditions ${ }^{[17-19]}$. Recently,more and more studies have demonstrated that MVs can delivered RNAs, DNA, and proteins to adjacent cells [20-23]. MVs are composed of various vesicle types, such as exosomes $(30-200 \mathrm{~nm})^{[24]}$. MicroRNAs (miRNAs) are non-coding RNAs that negatively regulate the mRNA transcription levels to impact gene expression. As determined by a number of studies, miRNAs take part in several cellular processes, including cell proliferation, cell apoptosis, and so on ${ }^{[25-27]}$. As reported, miRNAs are potential novel therapeutic targets for the treatment of OS ${ }^{[28]}$. Han I et al have previously suggested that miRNAs from serum show particular profiles in different types of cancer ${ }^{[29-31]}$. Previous studies have found that miR-6087 had obvious enrichment in hBMSCs-EXO ${ }^{[32]}$, and miR-6087 is one of the important miRNA species that is involved in tumorigenesis. Usuba W, Urabe F, et al. reported that miR-6087 plays an important role in the progression of bladder cancer. Therefore, early detection of circulating miRNA plates can be used to diagnose bladder cancer ${ }^{[33]}$.Jung $\mathrm{KY}$ et al. have identified endoglin gene as the target gene of miR$6087^{[34]}$. In our study,we indicate that hBMSC-derived exosomes play a key role in U2OS cell growth. Inhibition of miR-6087 in exosomes derived from hBMSCs significantly suppressed tumor growth.

\section{Materials And Methods}

\section{Cell culture}

Bone marrow was obtained from patients undergoing surgery for spine fracture with normal blood test results. We removed patients with hematologic disorders and familial genetic disorders. All patients agreed to participate in the study and this process was approved by the institutional review board of the First Affiliated Hospital of Nanchang University. A solution with a density of $1.073 \mathrm{~g} / \mathrm{mL}$, obtained by diluting Ficoll, was added to the separating tube. Then, fresh bone marrow was diluted with PBS and added to the Ficoll at a volume ratio of 4:3. Centrifugation was performed at room temperature at $400 \times \mathrm{g}$ for $30 \mathrm{~min}$. The second layers, a white cell band, comprised hBMSCs, and this was transferred to a new separating tube and washed three times with medium without FBS at $300 \times \mathrm{g}$ for 5 min. Finally, cells were resuspended and cultured in low-glucose $(1,000 \mathrm{mg} / \mathrm{L})$ DMEM supplemented with $10 \%$ exosome-depleted FBS and $100 \mu \mathrm{g} / \mathrm{L}$ penicillin-streptomycin in a humidified atmosphere containing $5 \% \mathrm{CO} 2$ at $37^{\circ} \mathrm{C}$. After 
$72 \mathrm{~h}$, unattached cells were washed and removed. Cells were then grown at $37^{\circ} \mathrm{C}$ for 3 weeks, during which the medium was changed every 3 days. hBMSCs were expanded until wall-attached cells reached $80 \%$ confluencelThen, culture supernatants from hBMSCs was harvested and hBMSCs were expanded.

\section{QRT-PCR}

We conducted assays to quantify mature miRNAs, as mentioned earlier, with some minor modifications ${ }^{[35,36]}$. Total RNA was extracted by the TRIzol Reagent (Servicebio), according to instructions. The levels of miRNA were quantitated using Taqman microRNA probes (ABI7500). The reactions were conducted in triplicate. While the reactions were running, the fixed threshold settings were used to determine the cycle threshold (CT) data, and the mean CT values were also calculated from triplicate RT-PCR assays.Comparative CT was applied to compare with the control reactions. The internal control for the miRNAs was U6 snRNA. The relative amounts of gene expression, which were normalized by the controls, were calculated using the Eq. $2-\triangle \mathrm{CT}$, in which $\triangle \mathrm{CT}=\mathrm{CT}$ gene - CT control. The miRNA6087 and U6 primers were designed as follows: 5'-CTCGCTTCGGCAGCACA-3' (U6, sense); 5'AACGCTTCACGAATTTGCGT-3' (U6, antisense); 5'-ACACTCCAGCTGGGTGAGGCGGGGGG-3' (miRNA-6087, sense); and 5'-TGGTGTCGTGGAGTCG - 3' (miRNA-6087, antisense).

\section{Transfection}

hBMSCs were seeded into a 6-well plate $24 \mathrm{~h}$ after the transfection experiment was conducted. Lentiviral particles containing the hsa-miR-6087-inhibitors that produce the antisense strand of hsa-miRNA-6087 and the randomized flanking sequence control were purchased from GeneChem (Shanghai, China) and transduced into hBMSCs, following the manufacturer's instructions. The cells were harvested at $72 \mathrm{~h}$ after transfection for PCR analysis.

\section{Isolation of MVs from media}

Samples were isolated from MSC culture medium as described previously ${ }^{[22]}$. In short, cell culture supernatants, containing vesicles, were centrifuged at 2,000 g for $30 \mathrm{~min}$ at $4{ }^{\circ} \mathrm{C}$, followed by centrifugation at $500 \mathrm{~g}$ for $5 \mathrm{~min}$, in order to remove cellular debris and large apoptotic bodies. After centrifugation, $16 \%$ PEG solution was added to the media at a ratio of $1: 1 \mathrm{v} / \mathrm{v}$, and the solution was incubated at $4{ }^{\circ} \mathrm{C}$ overnight, for at least $12 \mathrm{~h}$. The next day, the samples were centrifuged at $3,214 \mathrm{~g}$ (Eppendorf) for $1 \mathrm{~h}$ at $4{ }^{\circ} \mathrm{C}$. The supernatant was removed, and the centrifuge tube was inverted for 5 min, with occasional tapping to remove excess PEG. The sediment at the bottom of the centrifuge tube was suspended in $1 \mathrm{~mL}$ of particle-free PBS ( $\mathrm{pH} 7.4$ ), further purified with $8 \% \mathrm{PEG}$, and incubated at $4{ }^{\circ} \mathrm{C}$ overnight. On the third day, we repeated the previous day's procedures for the samples. Samples were finally resuspended in $50 \mu \mathrm{L}$ of particle-free PBS, and then, the exosomes could be used immediately or stored in liquid nitrogen, by shaking at room temperature for up to $30 \mathrm{~min}$.

\section{Transmission electron microscopy}


After fixing in a droplet of $2.5 \%$ glutaraldehyde in PBS buffer at $\mathrm{pH} 7.2$, the samples were fixed overnight at $4{ }^{\circ} \mathrm{C}$. The sample was dropped on copper wire for $20 \mathrm{~min}$ and the excess absorbed, and then, we used negative staining of the specimens in phosphotungstic acid for 1 minute at $25^{\circ} \mathrm{C}$, before observation through a FEI Tecnai T20 TEM at $120 \mathrm{kV}$.

\section{Cell viability}

The cell proliferation ability was tested by the CCK-8 assay. U2OS cells were co-cultured with normal exosomes $(400 \mu \mathrm{g} / \mathrm{mL})$ and miRNA-6087 downregulated exosomes $(400 \mu \mathrm{g} / \mathrm{mL})$, respectively, in a 96 well plate at $3 \times 103$ cells per well. In the control group, equal volume of exosome-depleted medium was added. Cell viability was measured at 6,12 , and $24 \mathrm{~h}$ after treatment with normal exosomes and miRNA6087 downregulated exosomes. The optical density (OD) value reflected the cell viability. The OD was measured at $450 \mathrm{~nm}$ by a enzyme standard instrument. The data are showed as the mean \pm SD.

\section{Scratch migration}

As conducted previously, the scratch migration assay was performed in the following experiment. In short, U2OS cells were plated at $1 \times 105$ cells per well in a 6-well plate and incubated at $37^{\circ} \mathrm{C}$ in a $5 \% \mathrm{CO} 2$ environment. When the cells covered $90 \%$ of the floor area, a scratch was drawn with a sterile $2 \mu \mathrm{L}$ pipette tip. Then, the wells were washed twice with PBS, after removing PBS with a $100 \mu \mathrm{L}$ pipette; exosomes $(400 \mu \mathrm{g} / \mathrm{mL})$ with or without downregulated miRNA-6087 and an equal volume of conditional medium served as the controls that were added to the cells. Under the microscope, the area of the scratch gap was recorded at 6,12 , or $24 \mathrm{~h}$.

\section{Transwell invasion}

In the invasion assay experiment, $5 \mathrm{~h}$ before seeding the cells, $40 \mu \mathrm{L}$ of diluted ECM glue was added to each chamber, and then, in the upper chamber, U2OS cells were plated at a density of $8 \times 104$ cells (24well ;8 $\mu \mathrm{m})$. Exosomes $(400 \mu \mathrm{g} / \mathrm{mL})$ or exosomes with downregulated miRNA-6087 $(400 \mu \mathrm{g} / \mathrm{mL})$ were cocultured with U2OS cells. The control group had an isometric exosome-depleted medium. Growth media $(600 \mu \mathrm{L})$ containing $30 \%$ FBS were added to the lower chamber of the Transwell as a chemoattractant. Invading cancer cells in the lower chamber were fixed in methanol for $20 \mathrm{~min}$ and stained with $0.1 \%$ crystal violet for $15 \mathrm{~min}$,after incubation for 24 hours in a $37^{\circ} \mathrm{C}$ incubator in $5 \% \mathrm{CO} 2$. We counted the number of cells invading the membrane under a microscope (20X, five random fields per well).

\section{Western blot analysis}

Alix and Hsp70 expression was detected by western blotting(GAPDH as internal reference). The immunoblots were blocked with blocking buffer (PBS containing $5 \%$ fat-free dried milk) at $25^{\circ} \mathrm{C}$ for $1 \mathrm{~h}$ and incubated at $4{ }^{\circ} \mathrm{C}$ overnight with anti-Alix and anti-Hsp70 (abcam, 1:1000) and anti-GAPDH (Abcam,1:2000) antibodies.

\section{Statistical analyses}


All data were obtained from five separate experiments. The data were expressed as the mean values \pm S.E. A P $<0.05$ was considered statistically significant by use of the t-test.

\section{Results}

\section{PEG-based vesicle enrichment can effectively gather hBMSCs-exo.}

In our research, firstly we cultured hBMSCs in the vitro(Figure 1).we selected an exosome isolation method that used PEG. Exosomes are microvesicles of 30-150 nm in size. In our study, we observed that exosomes were cup-shaped vesicles $100 \mathrm{~nm}$ in size, and western blotting assessed the expression of Hsp70 and ALIX in the hBMSC-exosomes (Fig. 2).

\section{Compared with hBMSCs, the expression of miRNA-6087 in exosomes derived from hBMSCs was significantly higher.}

We compared miRNA-6087 expression in the hBMSCs and hBMSC-exo using Q-PCR technology and found that the miRNA-6087 expression in exosomes was significantly higher than in hBMSCs. Therefore, we believe that the miRNA-6087 enrichment phenomenon was obvious in the exosomes and that this enrichment may promote the U2OS malignant phenotype (Fig. 3).

\section{Exosomes secreted from hBMSCs can effectively promote the proliferation, invasion, and migration of OS cells, but the exosomes derived from hBMSCs with downregulated miRNA-6087 cannot.}

In order to further address this, we conducted a scratch migration assay. U2OS cells treated with exosomes migrated nearly $90 \%$ of the scratch within $24 \mathrm{~h}$, while the cells cultured by the exosome-free medium could not migrate beyond the initial level after $24 \mathrm{~h}$. U2OS cells treated with exosomes with downregulated miRNA-6087 only migrated $10 \%$ and $20 \%$ of the scratch after $24 \mathrm{~h}$ of incubation (Fig. 4).

With the Transwell assay, we found that the human U20S cells showed enhanced invasion capacity after co-culturing with hBMSC-exosomes. However, this invasion capacity can be blocked by targeting miRNA6087. To eliminate the effect of the culture medium on the U2OS cells, we established a control group with the culture medium added. As expected, the invasion capacity of the control group was weakened(Fig. 4).

In the CCK-8 assay, we found that proliferation of U2OS cells increased by treatment with hBMSC-derived exosomes at $24 \mathrm{~h}$ (Fig. 4). However, in the hBMSC-derived exosomes treated with downregulated miRNA6087, the promoting effects were suppressed to a certain extent (Fig. 4). Therefore, it was suggested that miRNA-6087 in the exosomes derived from hBMSCs played a key role in the U2OS cancer cell growth.

\section{Discussion}

Osteosarcoma is a primary malignant tumor that occurs in the skeletal system, forming immature bone or bone-like tissue with tumor cells ${ }^{[37,38]}$.Kinoshita et al. found that exosomal miRs play an important role 
in the progression of a variety of human tumor cells ${ }^{[39]}$.In view of this, a study was conducted to evaluate the role of miR-6087 delivered by BMSC-exosomes in osteosarcoma together with its mechanisms. We found that exosomes derived from hBMSC can inhibit the proliferation, invasion and migration of U2OS cells by down-regulating miRNA-6087.

MV plays a crucial role in delivering miRNA-6087 into U20S cells. Recently,some studies have showed the potential use of MVs as safe and effective drug delivery vehicles [22, 40,41]. Johnson A et al. found that MVs secreted by hBMSCs contain miRNA, which may have specific interactions with internal environment and target cells [42]. Prockop DJ and Lee RH et al. demonstrated that MVs can transport components of the RNA-induced silencing complex (RISC) to target cells, suggesting that MVs participate in miRNAinduced gene silencing $[21,23,27,31,43]$. In this study, the MV we isolated can effectively transport miRNA-6087 to U2SO. We believe that exosomes are important carriers for cell-to-cell communication, and miRNA may regulate target cells through exosomes.Consistent with previously reported that modifying the surface of exosomes can promote the targeted uptake of contents by tumor cells[39, 44].One reason is that these MVs are derived from human cells, and thus have an inherent ability to reduce toxicity and enhance the tolerance of immune cells[45, 46].

In previous studies, many studies focused on the relationship between miRNA and OS malignant phenotype, and revealed some effects of miRNA on OS cell growth.Fa Qin et al. reported that Bone marrow-derived mesenchymal stem cell-derived exosomal microRNA-208a promotes osteosarcoma cell proliferation, migration, and invasion[47].As a member of miRNAs involved in tumor progression, miRNA6087 plays an important role in the progression of bladder cancer and liver cancer. We use miRNA-6087 to enrich exosomes in large quantities, and find that miRNA-6087 is down-regulated in exosomes. The proliferation, migration and invasion of U2OS cells were significantly inhibited. When U2OS cells were cultured with exosomes derived from hBMSC with down-regulated miRNA-6087, the proliferation, invasion and migration abilities of U2OS cells were significantly reduced, and even U2OS cell functions were also inhibited.

Taken together,We demonstrated for the first time the ability of hBMSC-derived exosomes to downregulate miRNA-6087 to inhibit the growth of U2OS cells. Our research provides the possibility of using drugs to down-regulate miRNA-6087 in exosomes to inhibit the progression of osteosarcoma.However, we will further verify our results through investigating the effect of miR-6087 on the expression of invasion-/migration-/apoptosis-related genes and supplementing the experiments with other osteosarcoma cell lines.

\section{Limitations}

Like most other research, our study has many shortcomings. First, we only conducted in vitro studies, and hope to perform in vivo studies in the future. Second, miR-6087 was only made to downregulate】and not upregulate. Therefore, we hope to evaluate the effects of upregulation of miR-6087 in hBMSC-exo. Third, our study was conducted on only one cell line, and we will try to verify the conclusions in other OS cell 
lines. Fourth, we did not study the related downstream molecular mechanism, but we will devote more attention to it in our subsequent study. Lastly, we need validation of the clinical specimens to verify our conclusions(The level of miRNA-6087 in the low-grade malignant osteosarcoma sample is significantly lower than a highly malignant sample of osteosarcoma), and the gene sequencing of the clinical specimens will be of great value for OS research.

\section{List Of Abbreviations}

hBMSCs, mesenchymal stem/stromal cells; HSP70, Heat Shock Protein 70; ALIX, ALG-2-interacting protein X; RT-PCR, reverse transcription-polymerase chain reaction. OS,Osteosarcoma; MVs, Microvesicles; miRNAs,MicroRNAs; FBS, fetal bovine serum; HUVECs ,Human umbilical vein endothelial cells; miRNAs, RNA-induced silencing complex; miRNAs,TNFR blocking peptide;

\section{Declarations}

\section{Ethics approval and consent to participate:}

The study protocol was approved by the Institutional Review Board of the First Affiliated Hospital of Nanchang University, and written informed consent was obtained from all study participants.

\section{Consent to publish:}

Not applicable.

\section{Availability of data and materials:}

The datasets during and/or analyzed during the current study are available from the corresponding author on reasonable request.

\section{Competing interests:}

The authors declare that they have no competing interests.

\section{Funding:}

This work was funded by Project supported by The Foundation of Health Department of Jiangxi Province(2016A073), Jiangxi Provincial Department of Science and Technology (20171BAB205059), Foundation of the Graduate Innovation Center, Jiangxi province,China(YC2017-S097), Gan-Po Talents Project 555 of Jiangxi Province and National Natural Science Foundation of China (NO.81660365)

\section{Acknowledgements:}

We greatly appreciate the assistance of the company Editage in Shanghai, which provided English language editing. 


\section{References}

1. Reed D R, Hayashi M, Wagner L, et al. Treatment pathway of bone sarcoma in children, adolescents, and young adults[J]. Cancer, 2017,123(12):2206-2218.

2. Shen P, Cheng Y. Long noncoding RNA IncARSR confers resistance to Adriamycin and promotes osteosarcoma progression[J]. Cell Death \& Disease, 2020,11(5).

3. Zhao G S, Zhang Q, Cao Y, et al. High expression of ID1 facilitates metastasis in human osteosarcoma by regulating the sensitivity of anoikis via PI3K/AKT depended suppression of the intrinsic apoptotic signaling pathway[J]. Am J Transl Res, 2019,11(4):2117-2139.

4. Pu F, Chen F, Zhang Z, et al. <p>Information Transfer and Biological Significance of Neoplastic Exosomes in the Tumor Microenvironment of Osteosarcoma</p>[J]. OncoTargets and Therapy, 2020,Volume 13:8931-8940.

5. Constantinidou A, Pollack S, Loggers E, et al. The evolution of systemic therapy in sarcoma[J]. Expert Review of Anticancer Therapy, 2014,13(2):211-223.

6. Ahmed A A, Zia H, Wagner L. Therapy resistance mechanisms in Ewing's sarcoma family tumors[J]. Cancer Chemotherapy and Pharmacology, 2014,73(4):657-663.

7. Philippe B, Luc S, Valérie P, et al. Culture and Use of Mesenchymal Stromal Cells in Phase I and II Clinical Trials[J]. Stem Cells International, 2010,2010:1-8.

8. Lin G L, Hankenson K D. Integration of BMP, Wnt, and notch signaling pathways in osteoblast differentiation[J]. Journal of Cellular Biochemistry, 2011,112(12):3491-3501.

9. MacKenzie T C, David A L, Flake A W, et al. Consensus statement from the first international conference for in utero stem cell transplantation and gene therapy[J]. Frontiers in Pharmacology, 2015,6 .

10. Otero-Vinas M, Falanga V. Mesenchymal Stem Cells in Chronic Wounds: The Spectrum from Basic to Advanced Therapy[J]. Adv Wound Care (New Rochelle), 2016,5(4):149-163.

11. Veletic I, Manshouri T, Multani A S, et al. Myelofibrosis osteoclasts are clonal and functionally impaired[J]. Blood, 2019,133(21):2320-2324.

12. Vacanti C A, Bonassar L J, Vacanti M P, et al. Replacement of an Avulsed Phalanx with TissueEngineered Bone[J]. New England Journal of Medicine, 2001,344(20):1511-1514.

13. Tu B, Zhu J, Liu S, et al. Mesenchymal stem cells promote osteosarcoma cell survival and drug resistance through activation of STAT3[J]. Oncotarget, 2016,7(30):48296-48308.

14. Ma Z, Cui X, Lu L, et al. Exosomes from glioma cells induce a tumor-like phenotype in mesenchymal stem cells by activating glycolysis[J]. Stem Cell Research \& Therapy, 2019,10(1).

15. Pelagalli A, Nardelli A, Fontanella R, et al. Inhibition of AQP1 Hampers Osteosarcoma and Hepatocellular Carcinoma Progression Mediated by Bone Marrow-Derived Mesenchymal Stem Cells[J]. Int J Mol Sci, 2016,17(7).

16. Vallabhaneni K C, Hassler M Y, Abraham A, et al. Mesenchymal Stem/Stromal Cells under Stress Increase Osteosarcoma Migration and Apoptosis Resistance via Extracellular Vesicle Mediated 
Communication[J]. PLoS One, 2016,11(11):e166027.

17. Pittenger M F. Multilineage Potential of Adult Human Mesenchymal Stem Cells[J]. Science (American Association for the Advancement of Science), 1999,284(5411):143-147.

18. Salem H K, Thiemermann C. Mesenchymal Stromal Cells â€" Current Understanding and Clinical Status[J]. Stem Cells, 2009:N/A-N/A.

19. Méndez-Ferrer S, Michurina T V, Ferraro F, et al. Mesenchymal and haematopoietic stem cells form a unique bone marrow niche[J]. Nature, 2010,466(7308):829-834.

20. Johnson A, Dorshkind K. Stromal cells in myeloid and lymphoid long-term bone marrow cultures can support multiple hemopoietic lineages and modulate their production of hemopoietic growth factors[J]. Blood, 1986,68(6):1348-1354.

21. Prockop D J. Marrow stromal cells as stem cells for nonhematopoietic tissues[J]. Science, 1997,276(5309):71-74.

22. Campagnoli C, Roberts I A, Kumar S, et al. Identification of mesenchymal stem/progenitor cells in human first-trimester fetal blood, liver, and bone marrow[J]. Blood, 2001,98(8):2396-2402.

23. Lee R H, Kim B, Choi I, et al. Characterization and Expression Analysis of Mesenchymal Stem Cells from Human Bone Marrow and Adipose Tissue[J]. Cellular physiology and biochemistry, 2004,14(46):311-324.

24. Yang J, Yu X, Xue F, et al. Exosomes derived from cardiomyocytes promote cardiac fibrosis via myocyte-fibroblast cross-talk[J]. Am J Transl Res, 2018,10(12):4350-4366.

25. Bruno S, Collino F, Deregibus M C, et al. Microvesicles Derived from Human Bone Marrow Mesenchymal Stem Cells Inhibit Tumor Growth[J]. Stem Cells and Development, 2013,22(5):758-771.

26. Sun K, Lai E C. Adult-specific functions of animal microRNAs[J]. Nature Reviews Genetics, 2013,14(8):535-548.

27. Rider M A, Hurwitz S N, Meckes D J. ExtraPEG: A Polyethylene Glycol-Based Method for Enrichment of Extracellular Vesicles[J]. Sci Rep, 2016,6:23978.

28. Jiang L, He A, Zhang Q, et al. miR-126 inhibits cell growth, invasion, and migration of osteosarcoma cells by downregulating ADAM-9[J]. Tumour Biol, 2014,35(12):12645-12654.

29. Lee J K, Park S R, Jung B K, et al. Exosomes derived from mesenchymal stem cells suppress angiogenesis by down-regulating VEGF expression in breast cancer cells[J]. PLoS One, 2013,8(12):e84256.

30. Han I, Yun M, Kim E O, et al. Umbilical cord tissue-derived mesenchymal stem cells induce apoptosis in PC-3 prostate cancer cells through activation of JNK and downregulation of PI3K/AKT signaling[J]. Stem Cell Res Ther, 2014,5(2):54.

31. Teng X, Chen L, Chen W, et al. Mesenchymal Stem Cell-Derived Exosomes Improve the Microenvironment of Infarcted Myocardium Contributing to Angiogenesis and Anti-Inflammation[J]. Cell Physiol Biochem, 2015,37(6):2415-2424. 
32. Baglio S R, Rooijers K, Koppers-Lalic D, et al. Human bone marrow- and adipose-mesenchymal stem cells secrete exosomes enriched in distinctive miRNA and tRNA species[J]. Stem Cell Res Ther, 2015,6:127.

33. Usuba W, Urabe F, Yamamoto Y, et al. Circulating miRNA panels for specific and early detection in bladder cancer[J]. Cancer Science, 2019,110(1):408-419.

34. Yoo J K, Kim J, Choi S J, et al. Discovery and Characterization of Novel MicroRNAs During Endothelial Differentiation of Human Embryonic Stem Cells[J]. Stem Cells and Development, 2012,21(11):2049-2057.

35. Nawaz M, Camussi G, Valadi H, et al. The emerging role of extracellular vesicles as biomarkers for urogenital cancers[J]. Nat Rev Urol, 2014,11(12):688-701.

36. Fatima F, Nawaz M. Vesiculated Long Non-Coding RNAs: Offshore Packages Deciphering TransRegulation between Cells, Cancer Progression and Resistance to Therapies[J]. Non-Coding RNA, 2017,3(1):10.

37. Wang Y, Liang T, Wang Y, et al. Long non-coding RNA AK093407 promotes proliferation and inhibits apoptosis of human osteosarcoma cells via STAT3 activation[J]. Am J Cancer Res, 2017,7(4):892902.

38. Pollino S, Palmerini E, Dozza B, et al. CXCR4 in human osteosarcoma malignant progression. The response of osteosarcoma cell lines to the fully human CXCR4 antibody MDX1338[J]. Journal of Bone Oncology, 2019,17:100239.

39. Katie E G, Róisín M D, Sanjay K S. Engineering Exosomes for Cancer Therapy[J]. International Journal of Molecular Sciences, 2017,18(6).

40. Yang L, Xie G, Fan Q, et al. Activation of the hedgehog-signaling pathway in human cancer and the clinical implications[J]. Oncogene, 2009,29(4):469-481.

41. Gradilla A C, Gonzalez E, Seijo I, et al. Exosomes as Hedgehog carriers in cytoneme-mediated transport and secretion[J]. Nat Commun, 2014,5:5649.

42. Fu J, Rodova M, Roy S K, et al. GANT-61 inhibits pancreatic cancer stem cell growth in vitro and in NOD/SCID/IL2R gamma null mice xenograft[J]. Cancer Lett, 2013,330(1):22-32.

43. Zhao L, Yu Y, Deng C. Protein and mRNA expression of Shh, Smo and Gli1 and inhibition by cyclopamine in hepatocytes of rats with chronic fluorosis[J]. Toxicology Letters, 2014,225(2):318324.

44. Olejarz W, Dominiak A, Żołnierzak A, et al. Tumor-Derived Exosomes in Immunosuppression and Immunotherapy[J]. Journal of Immunology Research, 2020,2020:1-11.

45. Théry $C$, Amigorena $S$, Raposo G, et al. Isolation and characterization of exosomes from cell culture supernatants and biological fluids[J]. Current protocols in cell biology, 2006,Chapter 3:3-22.

46. Dudakovic A, Camilleri E, Riester S M, et al. High-resolution molecular validation of self-renewal and spontaneous differentiation in clinical-grade adipose-tissue derived human mesenchymal stem cells[J]. J Cell Biochem, 2014,115(10):1816-1828. 
47. Qin $F$, Tang $H$, Zhang $Y$, et al. Bone marrow-derived mesenchymal stem cell-derived exosomal microRNA-208a promotes osteosarcoma cell proliferation, migration, and invasion[J]. Journal of Cellular Physiology, 2019,235(5):4734-4745.

\section{Figures}

A

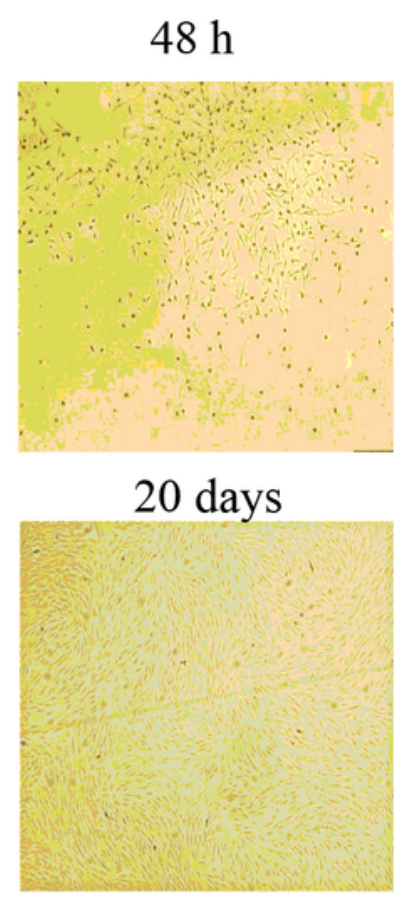

7 days

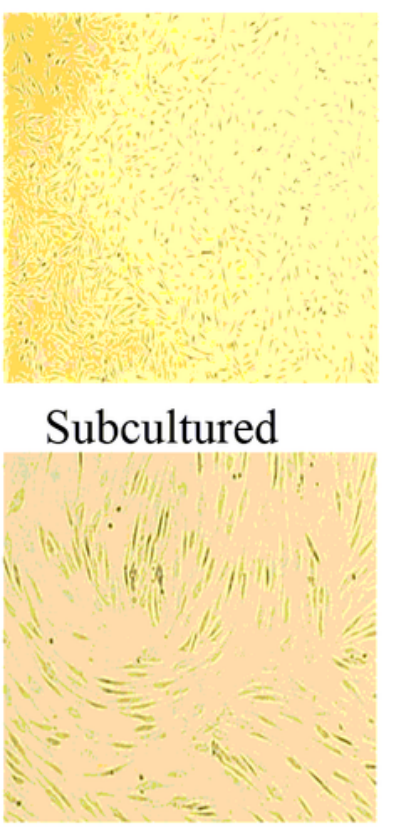

$\mathrm{C}$

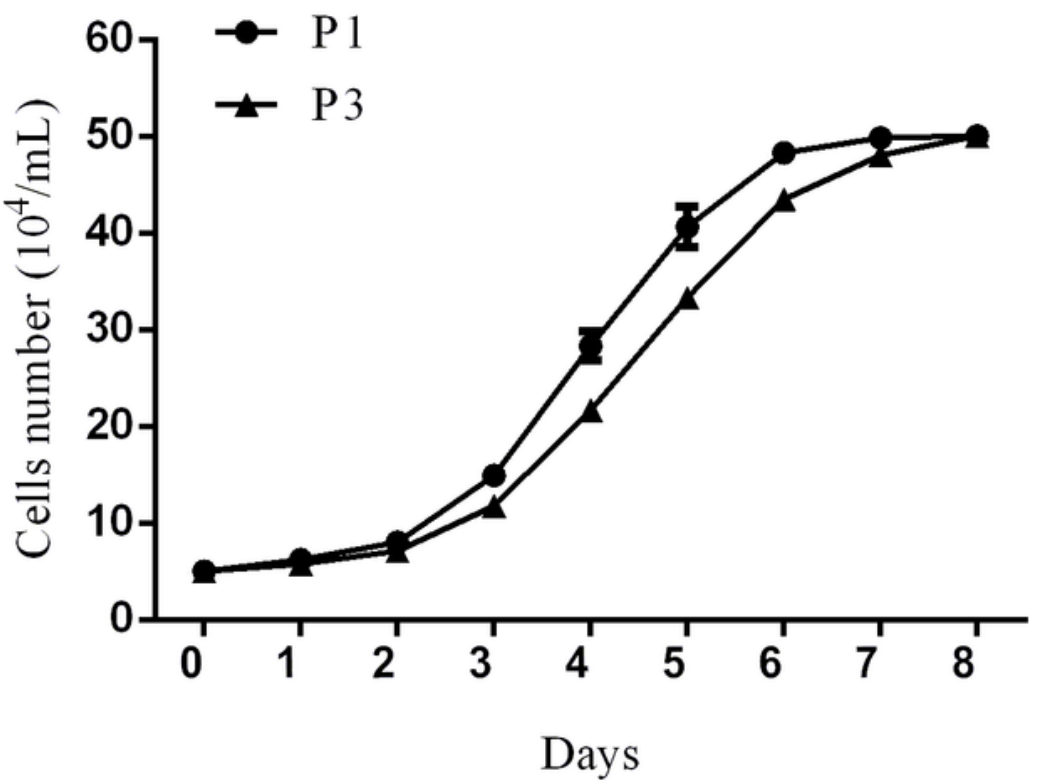

B
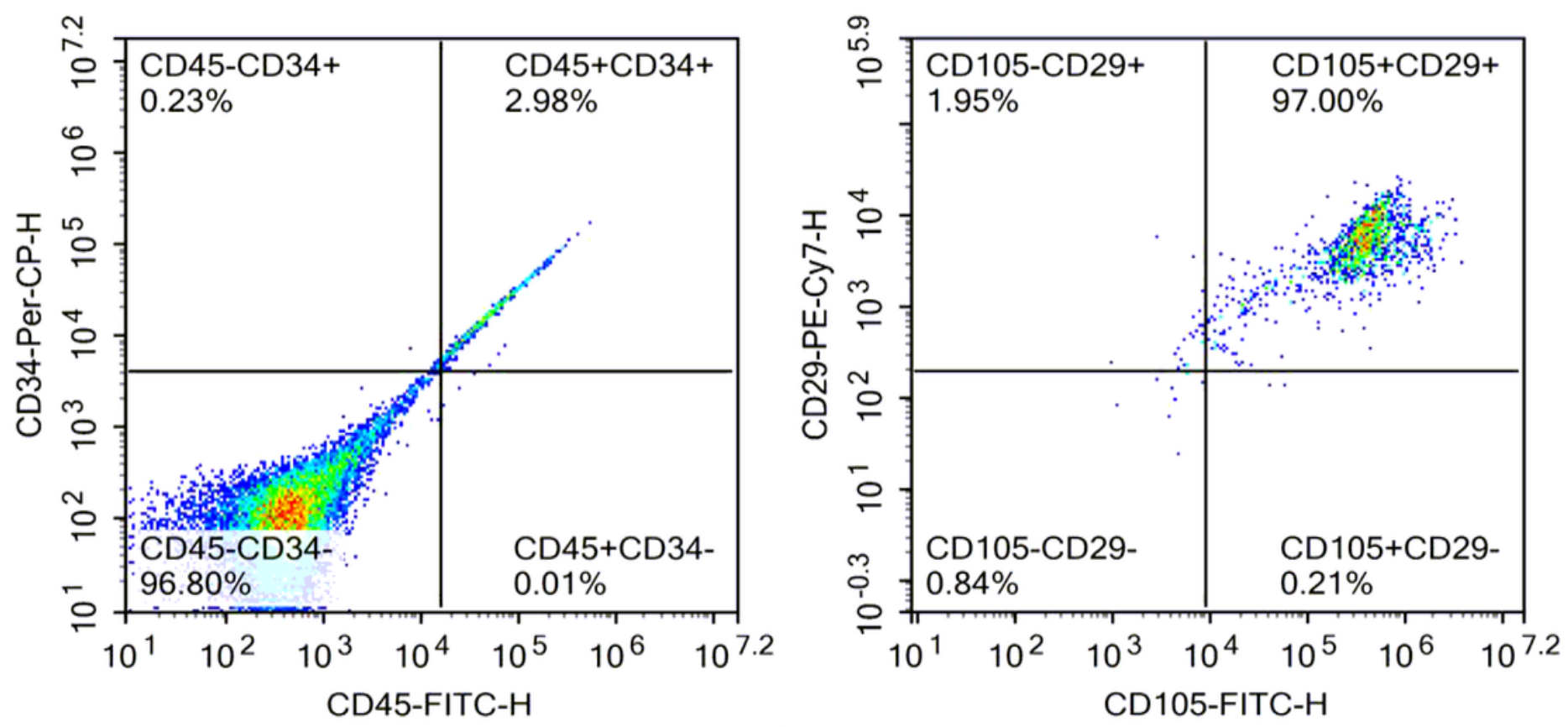

Figure 1 
Characterization of human bone marrow-derived mesenchymal stem cells. A $\backslash$ The cell morphology of human bone marrow-derived MSCs was observed at 3rd passage; grew as a fibroblast-like, spindle shaped morphology of cells were represented under light microscope. B: Human bone marrow-derived MSCs phenotypes detected by FACS analysis, showing positive expression of CD29, CD34, and CD105 markers, while negative expression for CD45 markers.

A

$48 \mathrm{~h}$

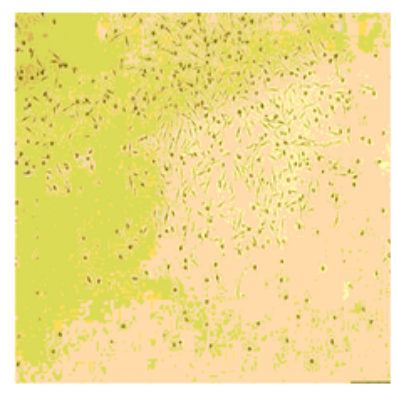

20 days

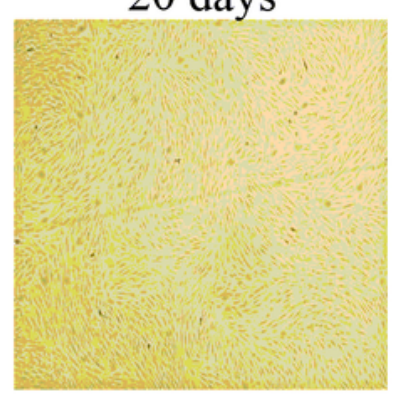

7 days

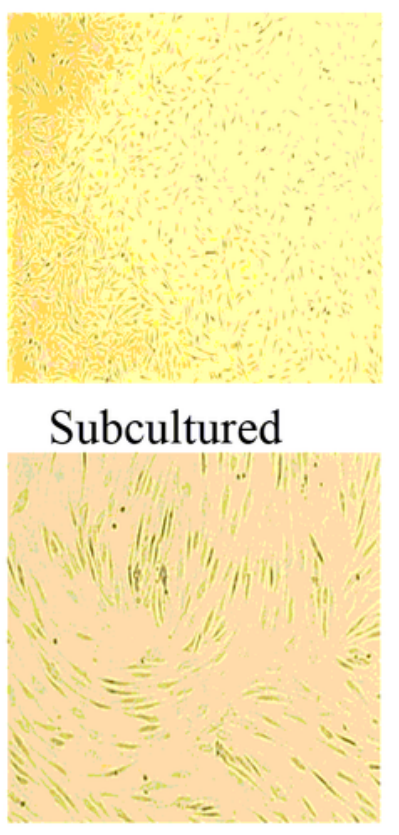

$\mathrm{C}$

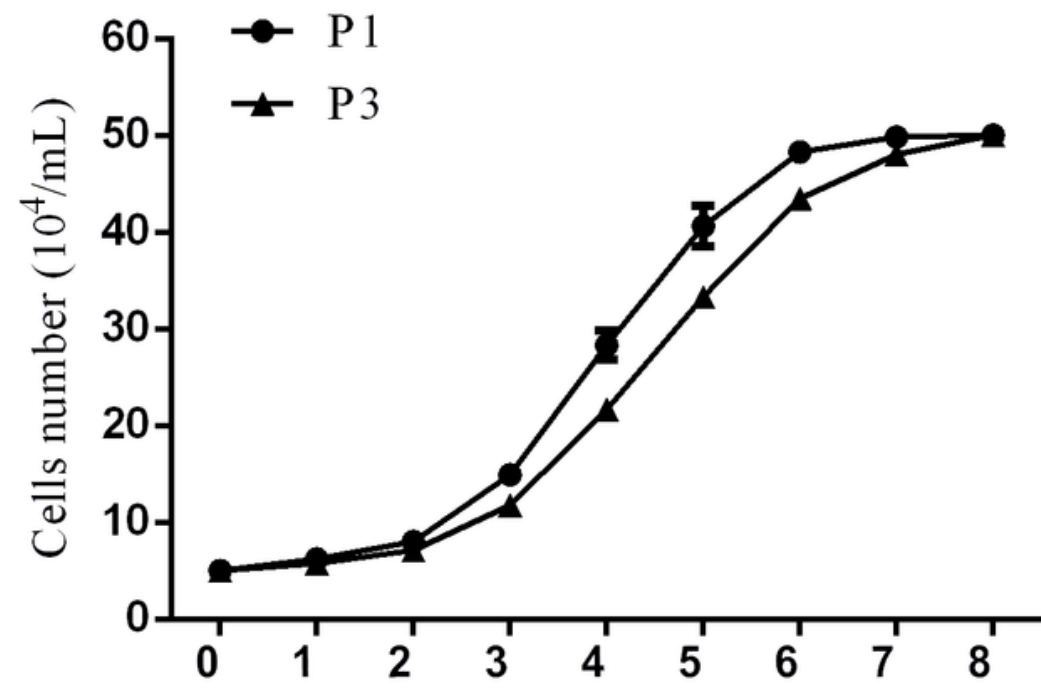

Days

B
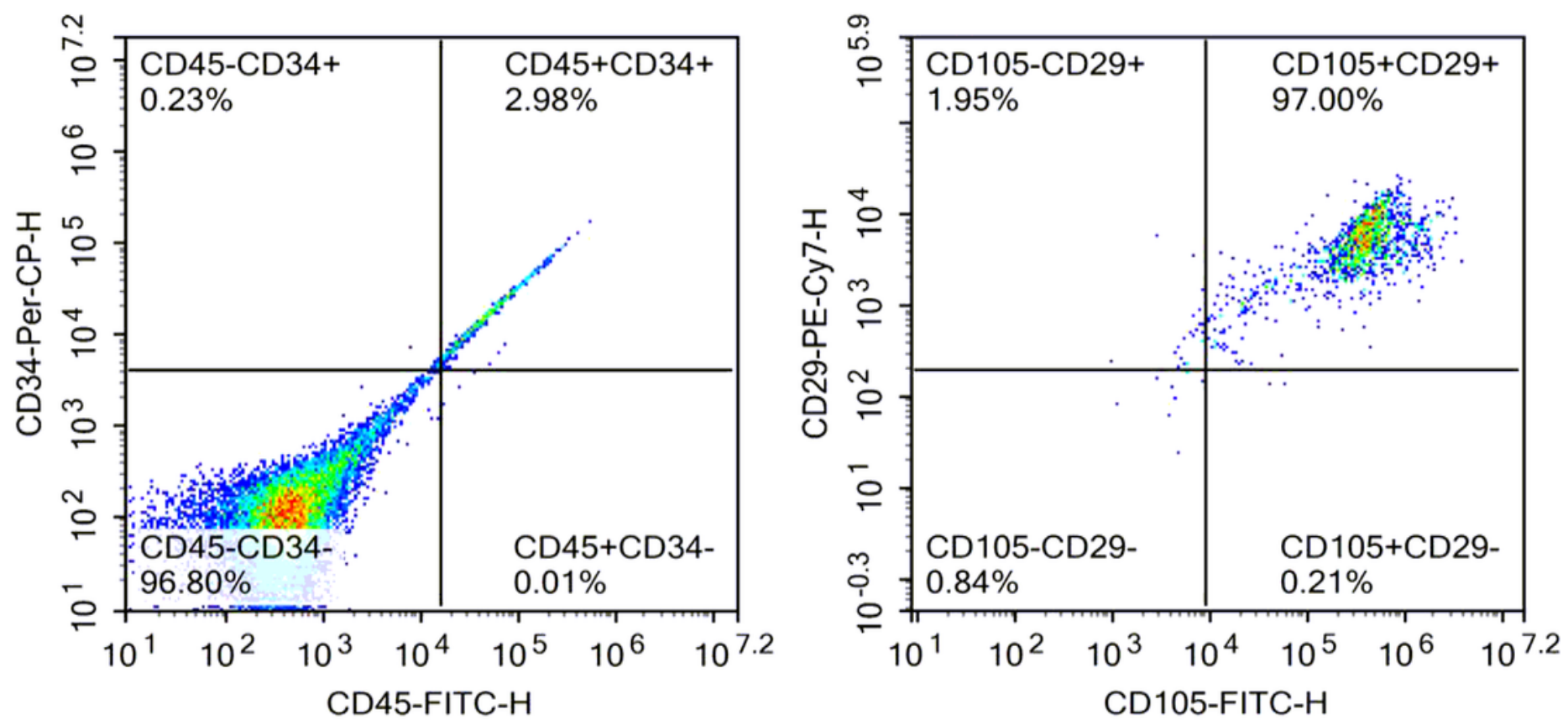

Figure 1 
Characterization of human bone marrow-derived mesenchymal stem cells. A囚The cell morphology of human bone marrow-derived MSCs was observed at 3rd passage; grew as a fibroblast-like, spindle shaped morphology of cells were represented under light microscope. B: Human bone marrow-derived MSCs phenotypes detected by FACS analysis, showing positive expression of CD29, CD34, and CD105 markers, while negative expression for CD45 markers.
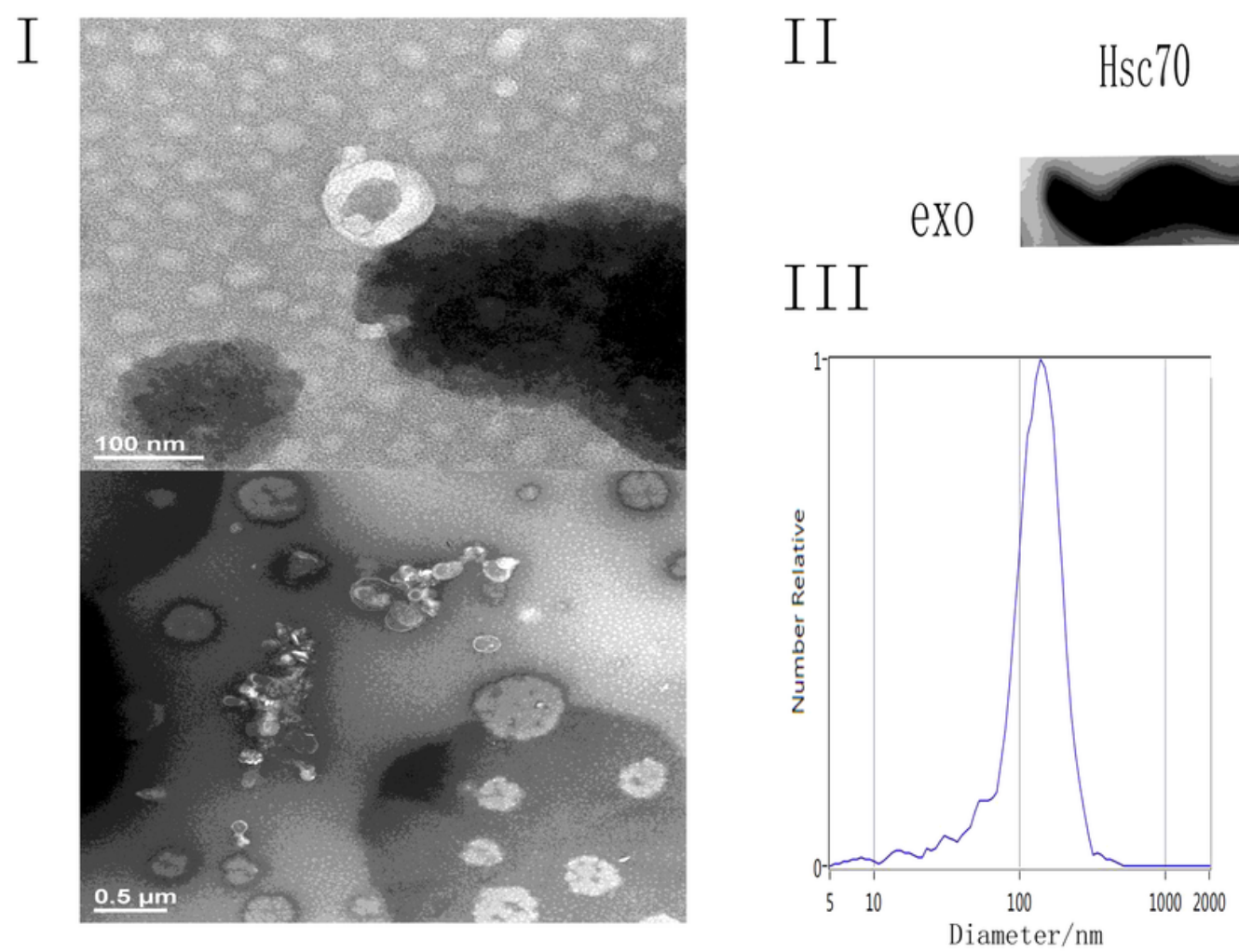

Alix

\section{Figure 2}

Identification and characterization of exosomes secreted by human bone marrow-derived MSCs. (I and II) Transmission electron microscopy images of exosomes derived from MSCs revealed typical small round nanoparticles with a diameter ranging from 40 to $150 \mathrm{~nm}$. The scale bars indicate $100 \mathrm{~nm}$ and $0.5 \mathrm{um}$. (II) Detection of Hsp70 and ALIX expression in hBMSC-exosomes by western blotting. 


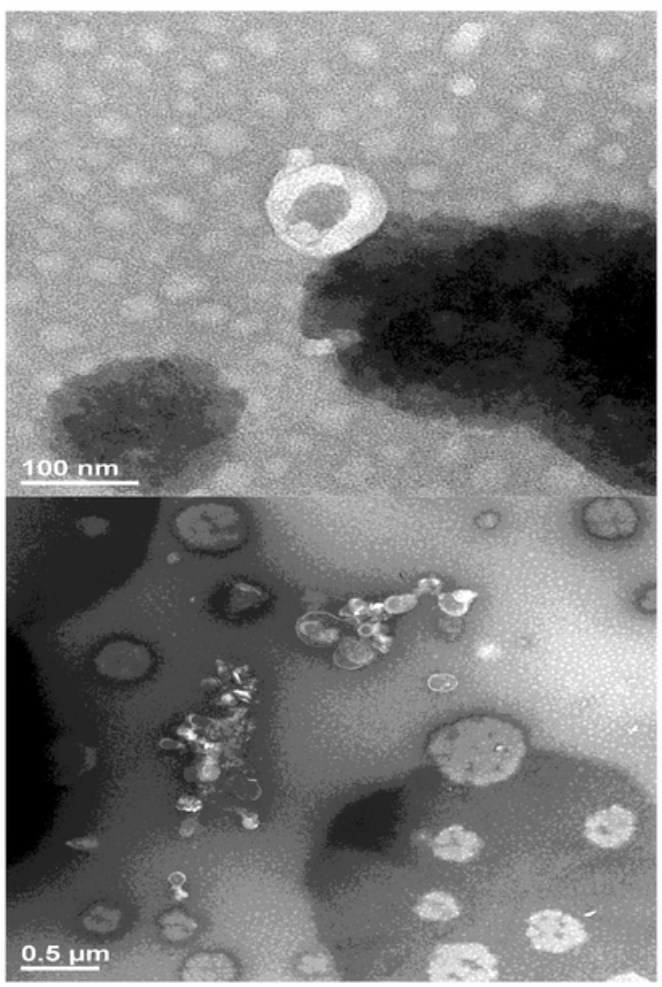

II

Hsc70

Alix
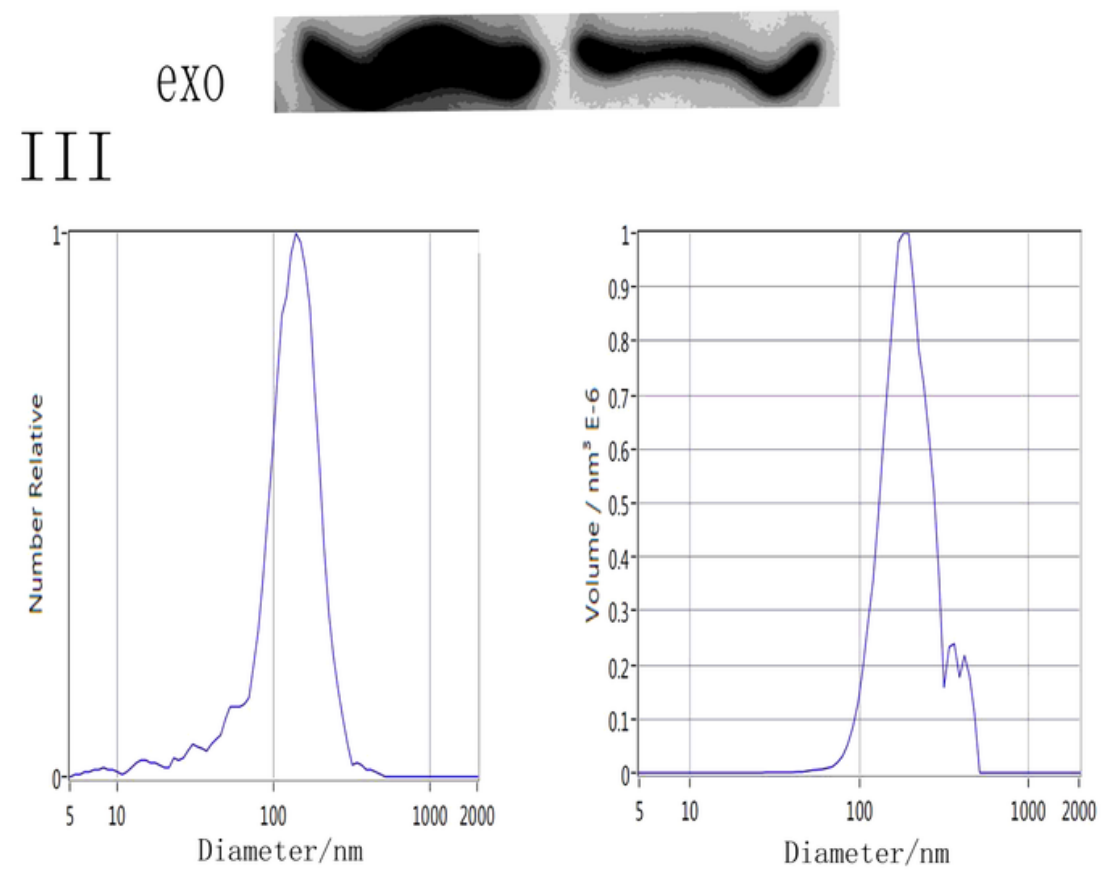

Figure 2

Identification and characterization of exosomes secreted by human bone marrow-derived MSCs. (I and II) Transmission electron microscopy images of exosomes derived from MSCs revealed typical small round nanoparticles with a diameter ranging from 40 to $150 \mathrm{~nm}$. The scale bars indicate $100 \mathrm{~nm}$ and $0.5 \mathrm{um}$. (II) Detection of Hsp70 and ALIX expression in hBMSC-exosomes by western blotting.

\section{mir6087}

\subsection{0}

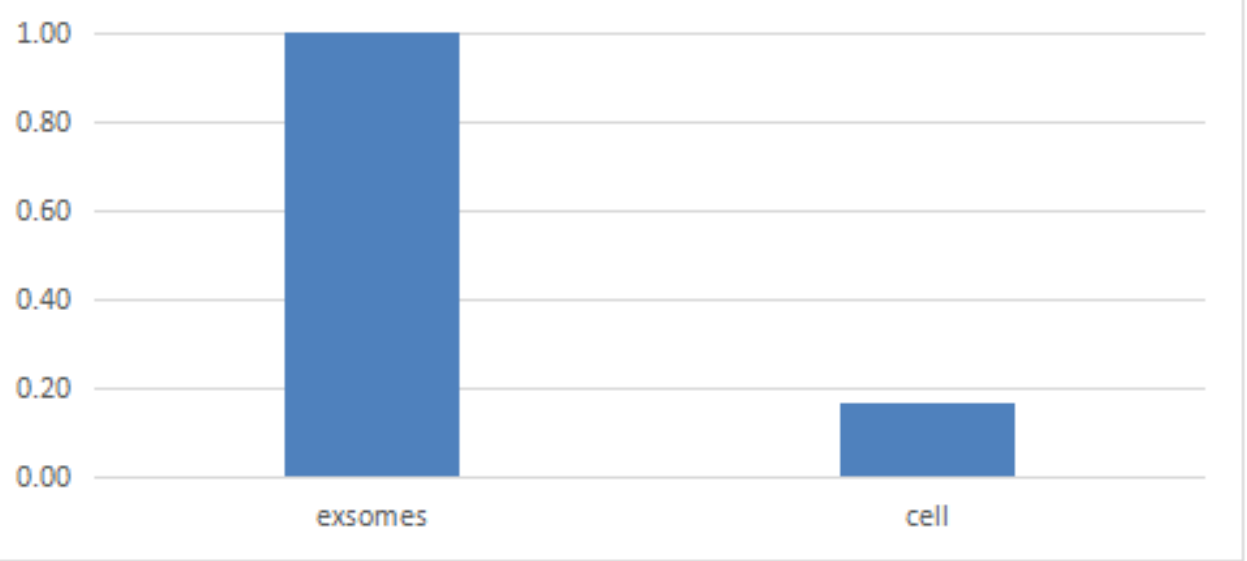

\section{Figure 3}


Expression of miRNA-6087 in exosomes and hBMSCs $\triangle \mathrm{U} 6$ as a reference gene, the abundance of exosome MiRNA6087 was standardized to $1 \rrbracket$

\section{mir6087}

\subsection{0}

1.00

0.80

0.60

0.40

0.20

0.00

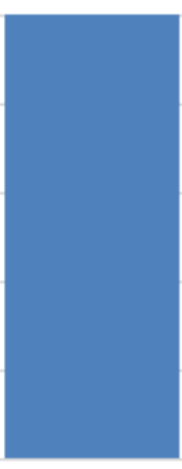

exsomes

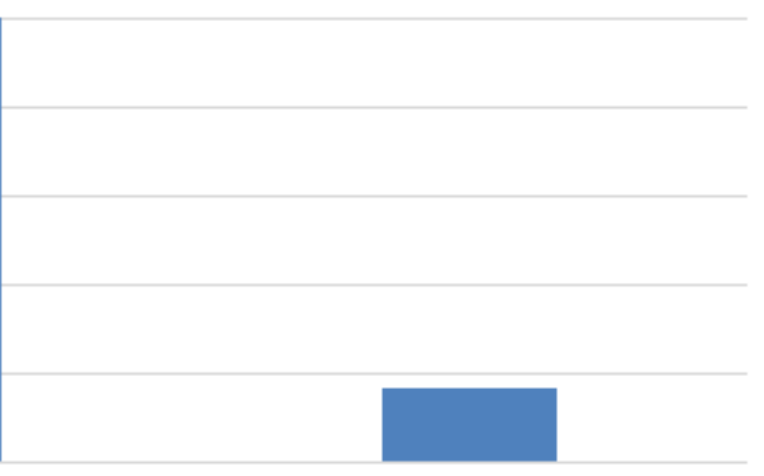

cell

\section{Figure 3}

Expression of miRNA-6087 in exosomes and hBMSCs $\triangle \mathrm{U} 6$ as a reference gene, the abundance of exosome MiRNA6087 was standardized to 1 区

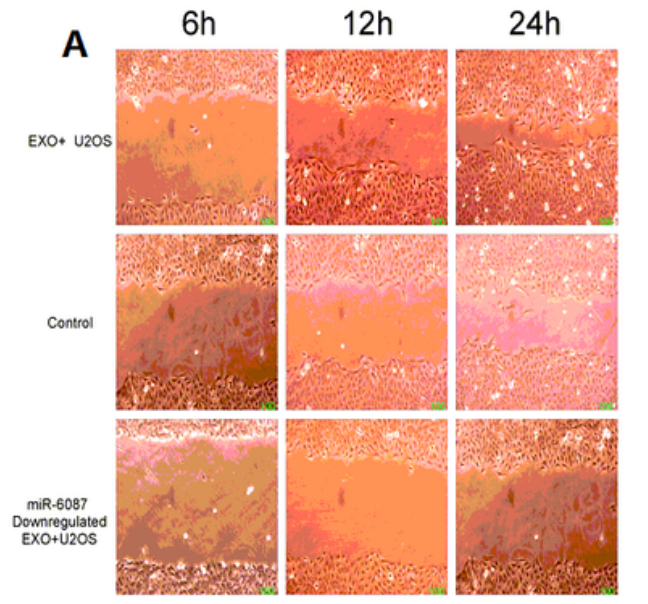

D
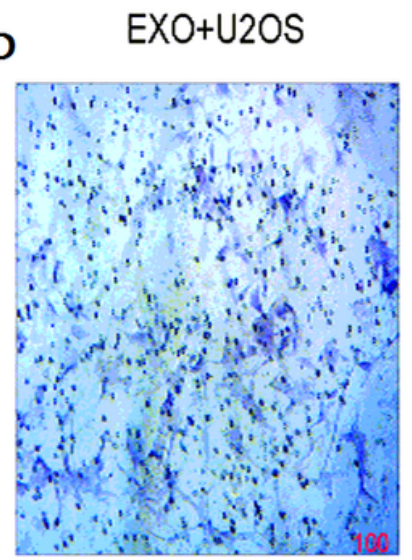

B

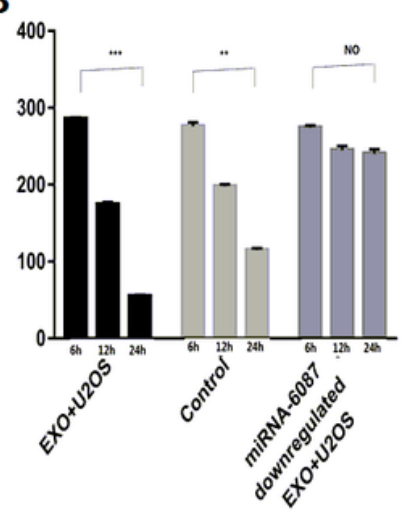

miR-6087 downregulated

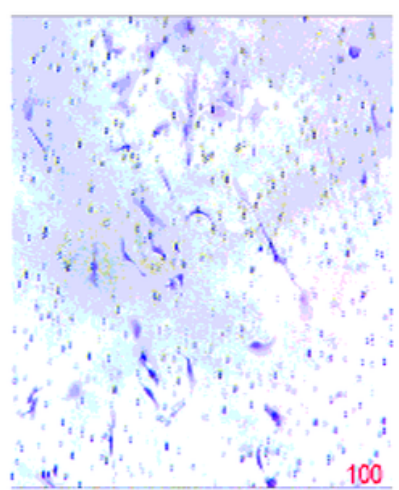
$\mathrm{EXO}+\mathrm{U} 2 \mathrm{OS}$

Control

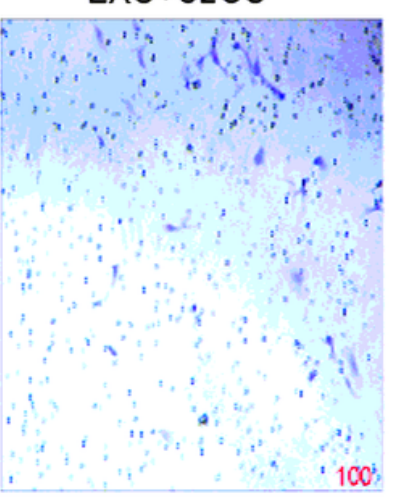

C
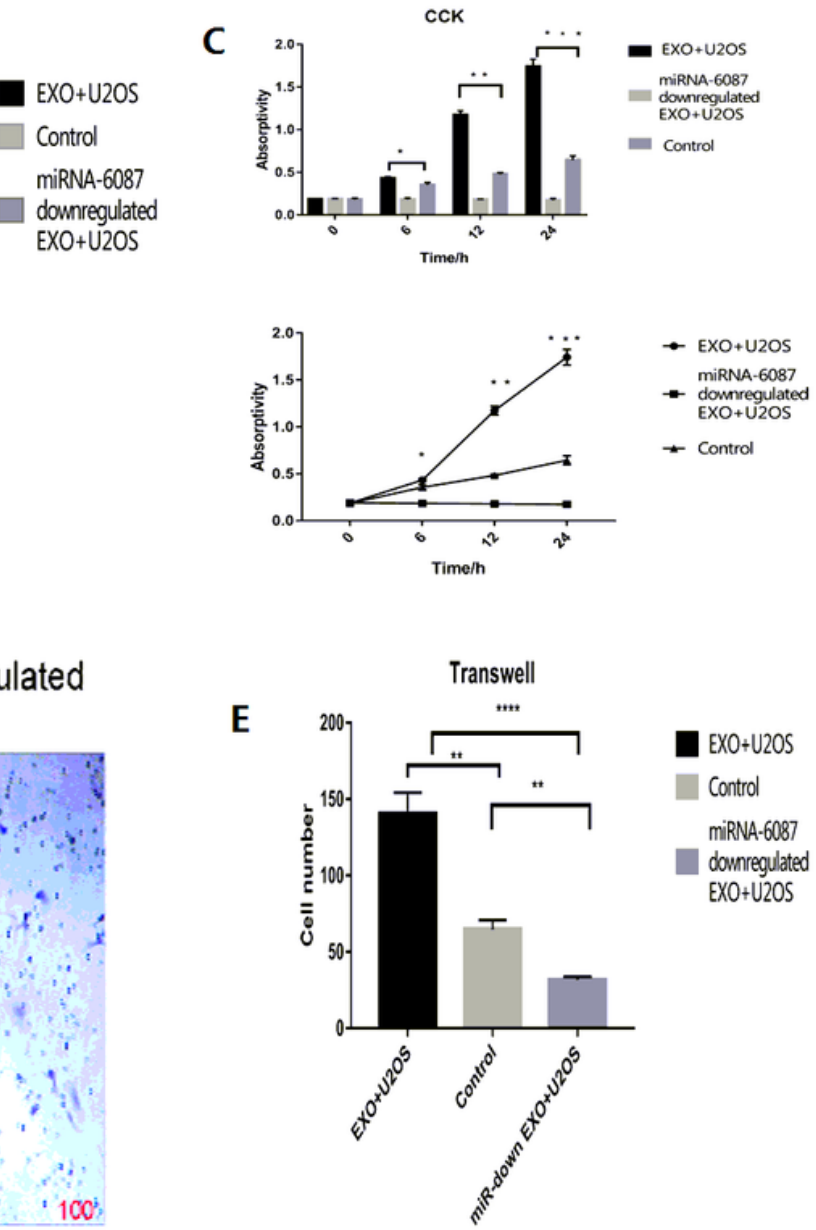


\section{Figure 4}

hBMSC-exosomes induce viability and proliferation in U2OS cells. A and B: Scratch migration assay test of interfering hBMSC-exosomes group, miR-6087down-regulated group and control group in $6,12,24$ hours. The wound healing assay demonstrated a stronger migration ability of cells in hBMSC-exosomes group. Compared with control group and miR-6087down-regulated group, there were significant difference in percentage of wound closed( $n=3$ per group).a weaker migration ability of cells in the blank control and miR-6087down-regulated group. CखU2OS cells were re-spectively co-cultured with concentration of hBMSC-exosomes $(400 \mu \mathrm{g} / \mathrm{ml})$ for $0 \llbracket 6 \otimes 12 \rrbracket 24$ hours and then subjected to CCK-8 analyses. $\mathrm{n}=3$ per group. $\mathrm{D}$ and $\mathrm{EX}$ an amounts of U2OS cells were respectively added to the upper chamber of transwell with matrigel coated membrane. Cancer cells were treated with exosomes $(400 \mu \mathrm{g} / \mathrm{ml})$ or treated with miR-6087 down-regulated exosomes $(400 \mu \mathrm{g} / \mathrm{ml})$, an equal volume of exosome-depleted medium was used as a control. After 24 hours the number of cells migrated to the lower chamber of the $8 \mu \mathrm{m}$ pore-sized membrane were analyzed by taking photos and counting the number of cells per visual field. $n=3$ per group. ${ }^{\star \star \star *} p<0.001 .{ }^{\star \star \star} p<0.005 .{ }^{* \star} p<0.01 .{ }^{\star} p<0.05$.NO:no statistically significant

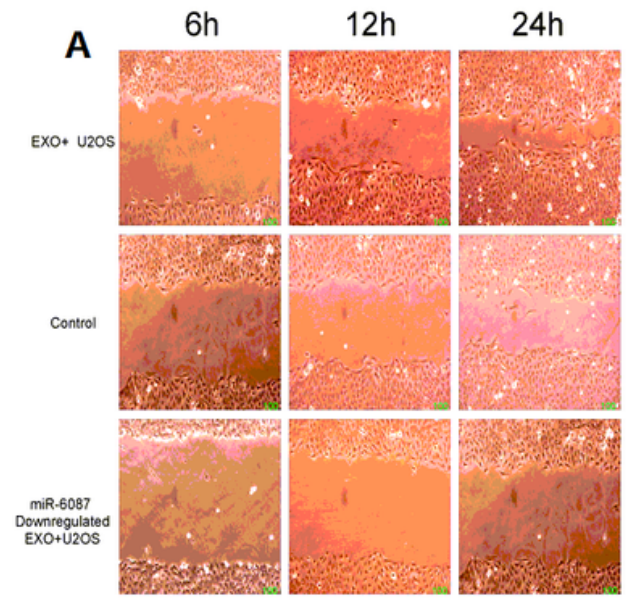

D EXO+U2OS

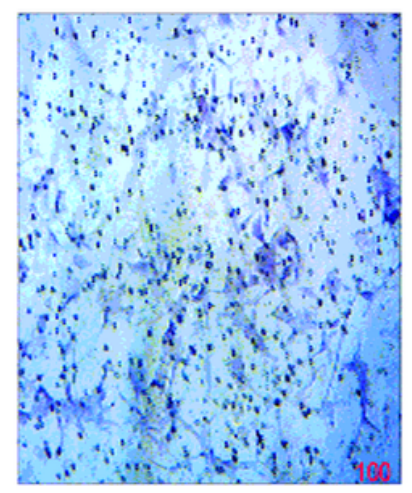

Control

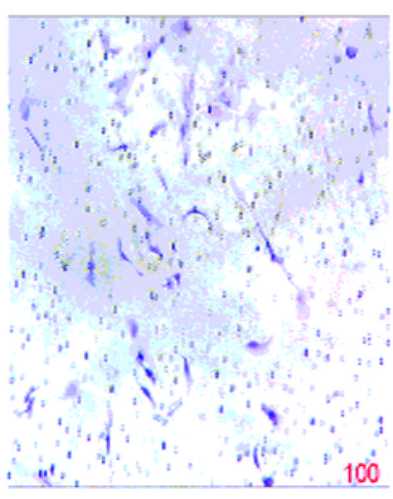

Data 1

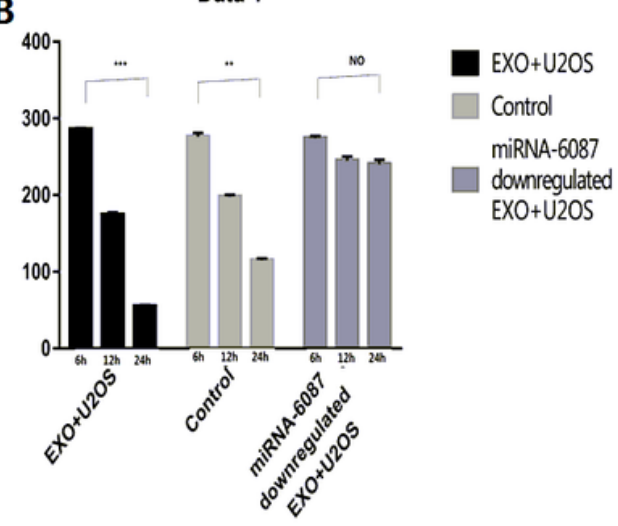

miR-6087 downregulated EXO+U2OS

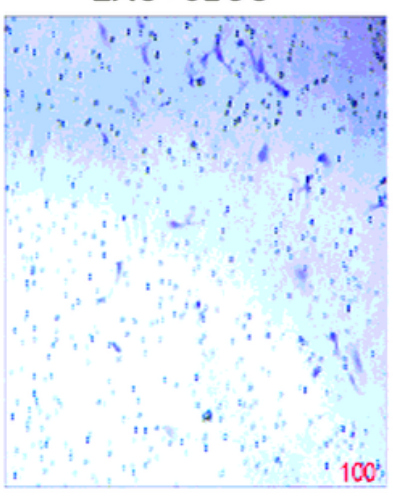

C
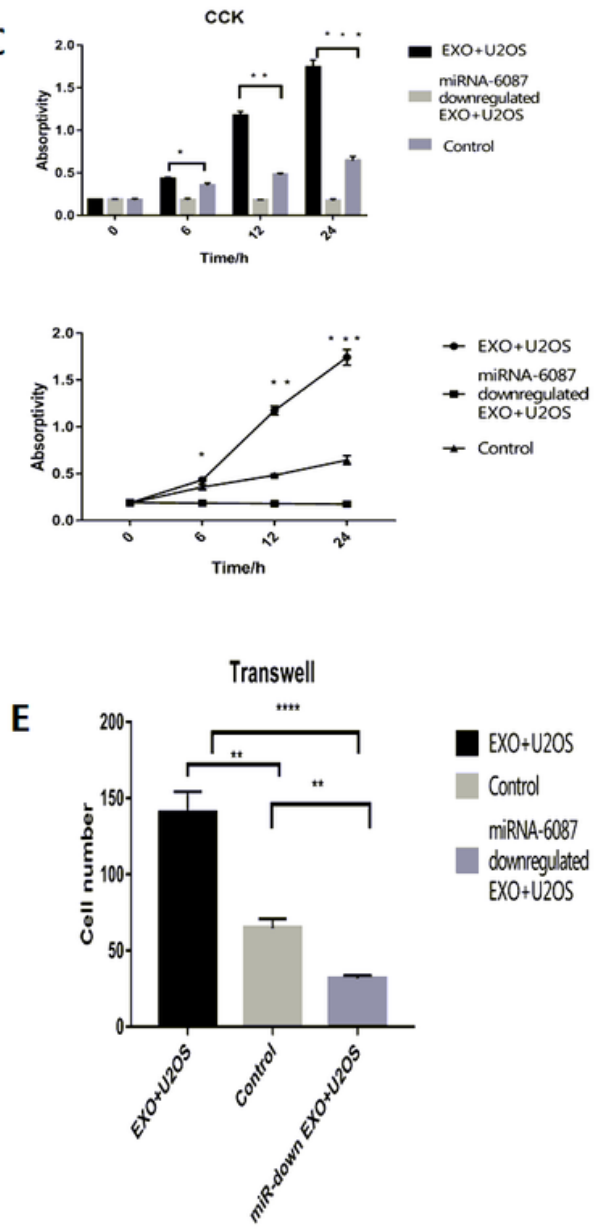

\section{Figure 4}


hBMSC-exosomes induce viability and proliferation in U2OS cells. A and B: Scratch migration assay test of interfering hBMSC-exosomes group, miR-6087down-regulated group and control group in $6,12,24$ hours. The wound healing assay demonstrated a stronger migration ability of cells in hBMSC-exosomes group. Compared with control group and miR-6087down-regulated group, there were significant difference in percentage of wound closed( $n=3$ per group).a weaker migration ability of cells in the blank control and miR-6087down-regulated group. CखU2OS cells were re-spectively co-cultured with concentration of hBMSC-exosomes $(400 \mu \mathrm{g} / \mathrm{ml})$ for $0 \llbracket 6 \otimes 12 \rrbracket 24$ hours and then subjected to CCK-8 analyses. $n=3$ per group. $D$ and $E \mathbb{Z}$ an amounts of U2OS cells were respectively added to the upper chamber of transwell with matrigel coated membrane. Cancer cells were treated with exosomes $(400 \mu \mathrm{g} / \mathrm{ml})$ or treated with miR-6087 down-regulated exosomes $(400 \mu \mathrm{g} / \mathrm{ml})$, an equal volume of exosome-depleted medium was used as a control. After 24 hours the number of cells migrated to the lower chamber of the $8 \mu \mathrm{m}$ pore-sized membrane were analyzed by taking photos and counting the number of cells per visual field. $n=3$ per group. ${ }^{\star \star \star *} p<0.001 .{ }^{* \star *} p<0.005$. ${ }^{* \star} p<0.01 .{ }^{*} p<0.05$.NO:no statistically significant 